\title{
МАТЕМАТИЧЕСКИЕ ВЫРАЖЕНИЯ В ФОРМУЛЕ ИЗОБРЕТЕНИЙ В ОБЛАСТИ ХИМИИ
}

\author{
(Представил О. Киррет)
}

Математизация знаний - типичное явление современной науки и техники. Характеристика изобретательского объекта защиты математическими зависимостями не представляет собой какой-либо редкости в патентных формулах, тем более что многие простейшие или несложные зависимости обычно выражаются словами, например, «температуру повышают пропорционально давлению», «очертание кулачка в форме логарифмической спирали» и т.д.

Однако встречаются такие изобретения, особенности которых заключаются в сложных соотношениях параметров, например, оптимизации некоторых химических процессов. Словесная характеристика этих соотношений оказывается чрезмерно сложной как в изложении, так и в понимании, и гораздо проще отображать их в виде математических формул. При современном развитии химии и глубоких исследованиях изобретения, описываемые сложными математическими завнсимостями, появляются все чаще.

Количественные отличия могут быть записаны в формуле изобретения цифрами или математическими формулами. Цифровые количественные отличия выражаются либо относительными, либо абсолютными величинами.

В целях определения частоты употребительности математических выражений в формулах изобретений нами было проанализировано более 2000 формул изобретений, опубликованных в официальном бюллетене «Открытия, изобретения, промышленные образцы, товарные знаки» за 1980 г. и в бюллетене «Открытия, изобретения» за 1983 г. Полученные статистические данные приведеңы в табл. 1. [']. Число формул изобретений, в которых для описания существенных признаков применены математические выражения, неуклонно растет (табл. 1). Для изучения этой закономерности и выяснения, какая роль в этом росте отведена формуле в области химии, и предпринято настоящее исследование.

Среди опубликованных в 1977, 1980 и 1983 гг. формул изобретений математические выражения встречались прежде всего в следующих разделах: $G$ (Физика), $B$ (Различные технологические процессы), $H$ (Электричество), C (Химия), т. е. в тех областях знаний, в которых существующие закономерности принято выражать математическим языком (см. табл. 2).

Химия тесно связана с разделами $G$ и $B$. Для «вооружения» химиков знанием приемов защиты своих формул и математических выражений, как это успешно делается в академиях наук Украинской и Белорусской ССР, проанализируем изобретения, в формулах которых использованы математические выражения. При этом математическое 
Количество формул изобретений, в которых использованы математические выражения

\begin{tabular}{|c|c|c|c|c|c|c|c|}
\hline \multirow{3}{*}{ Год } & \multirow{3}{*}{$\begin{array}{c}\text { Общее } \\
\text { число } \\
\text { опублико- } \\
\text { ванных } \\
\text { формул } \\
\text { изобретений }\end{array}$} & \multirow{2}{*}{\multicolumn{2}{|c|}{$\begin{array}{c}\text { Формулы изобрете- } \\
\text { ний, содержащие } \\
\text { математические } \\
\text { выражения }\end{array}$}} & \multicolumn{4}{|c|}{$\begin{array}{c}\text { Распределение формул изобретеннй } \\
\text { по видам объектов }\end{array}$} \\
\hline & & & & \multicolumn{2}{|c|}{ Способы } & \multicolumn{2}{|c|}{ Устройства } \\
\hline & & Число & $\begin{array}{c}\% \text { от } \\
\text { общего } \\
\text { числа }\end{array}$ & Число & $\%$ & Число & $\%$ \\
\hline $\begin{array}{l}1969 \\
1970 \\
1974 \\
1975 \\
1977 \\
1980 \\
1983\end{array}$ & $\begin{array}{l}22190 \\
26663 \\
38200 \\
36530 \\
38933 \\
85883 \\
78569\end{array}$ & $\begin{array}{r}77 \\
98 \\
172 \\
227 \\
540 \\
1154 \\
1430\end{array}$ & $\begin{array}{l}0,34 \\
0,37 \\
0,45 \\
0,62 \\
1,38 \\
1,34 \\
1,82\end{array}$ & $\begin{array}{r}38 \\
45 \\
65 \\
91 \\
200 \\
527 \\
601\end{array}$ & $\begin{array}{l}49,35 \\
45,92 \\
37,79 \\
40,09 \\
37 \\
45,67 \\
42\end{array}$ & $\begin{array}{r}39 \\
53 \\
107 \\
136 \\
340 \\
627 \\
829\end{array}$ & $\begin{array}{l}50,65 \\
54,08 \\
62,21 \\
59,91 \\
63 \\
54,33 \\
58\end{array}$ \\
\hline
\end{tabular}

выражение понимается как комбинация символов величин и знаков операций, составленная согласно правилам математики и имеющая определенный физико-технический смысл.

В Инструкции $\left[{ }^{2}\right]$ выделено несколько видов количественных признаков:

1) соотношение ингредиентов вещества, полученного нехимическим путем;

2) химическая связь и состав атомов химических соединений;

3) соотношение геометрических и физических параметров объекта;

4) абсолютные значения геометрических или физических параметров, характеризующих объект;

5) физические соотношения параметров объекта, характеризующие режим способа;

6) завершающая операция способа измерения;

7) закон управления какой-либо величиной;

8) передаточная функция звена системы регулирования.

Количественные признаки 4-го пункта обычно представляют в форме диапазона численных значений, остальные - в форме математического выражения (уравнения, зависимости) $\left[{ }^{2-4}\right]$.

Устройство как объект изобретения. В этом случае математическими зависимостями чаще всего выражаются новые соотношения размеров и других одноразмерных параметров какого-либо элемента или элементов. Математические зависимости в формулах изобретения могут выражать признаки взаиморасположения элементов.

Рассмотрим, например, формулу изобретения по авторскому свидетельству № 741147 «Газовый хроматограф». Изобретение относится к области количественного анализа методом газожидкостной хроматографии и может быть применено в аналитических лабораториях.

По изобретению № 272655 известен газовый хроматограф, в котором выход устройства, куда вводится проба, соединен дополнительным каналом с входом в детектор. Сечение и длину этого канала выбирают так, чтобы небольшая часть пробы, минуя разделительную колонку, попадала в детектор. Недостатком этого хроматографа является малый объем дополнительного канала, отчего выходящая из него с большой скоростью проба выплескивается узким пиком с крутым передним фронтом. Устройство не успевает отреагировать на такие скорости, и поэтому высота соответствующего пика оказывается не пропорциональ- 
Количество математических выражений по разделам международной классификации изобретений (МКИ)

\begin{tabular}{|c|c|c|c|c|c|}
\hline \multirow{2}{*}{$\begin{array}{c}\text { Раздел } \\
\text { МКИ }\end{array}$} & \multicolumn{3}{|c|}{1977} & \multirow[b]{2}{*}{1980} & \multirow[b]{2}{*}{1983} \\
\hline & $\begin{array}{l}\text { по спо- } \\
\text { собам }\end{array}$ & $\begin{array}{c}\text { по уст- } \\
\text { ройствам }\end{array}$ & всего & & \\
\hline $\begin{array}{l}\text { A } \\
\text { B } \\
\text { C } \\
\text { D } \\
\text { E } \\
\text { F } \\
\text { G } \\
\text { H }\end{array}$ & $\begin{array}{r}1 \\
52 \\
11 \\
2 \\
4 \\
6 \\
96 \\
28\end{array}$ & $\begin{array}{r}4 \\
61 \\
7 \\
2 \\
13 \\
46 \\
124 \\
83\end{array}$ & $\begin{array}{r}5 \\
113 \\
18 \\
4 \\
17 \\
52 \\
520 \\
111\end{array}$ & $\begin{array}{r}22 \\
329 \\
46 \\
23 \\
68 \\
100 \\
397 \\
164\end{array}$ & $\begin{array}{r}61 \\
390 \\
56 \\
15 \\
131 \\
106 \\
492 \\
176\end{array}$ \\
\hline
\end{tabular}

ной общему объему введенной пробы. Вследствие этого получаются невоспроизводимые результаты количественного анализа.

Цель изобретения № 741147 - повышение точности анализа. Для этого в предлагаемом хроматографе на линии дополнительного канала установлена размывающая емкость, максимальный объем которой определяется поо формуле:

$$
V=5,1 \cdot 10^{4} \cdot \frac{V d}{M P_{a}}
$$

где $\quad V$ - максимальный объем жидкой пробы, предусмотренной хроматографической методикой, мкл;

$d, M$ - удельный и молекулярный веса пробы, г/мл и г;

$P_{a}$ - абсолютное давление на входе в колонку, мм рт. ст.

Количественные признаки, характеризующие способы, это параметры режимов: температура, давление, время, скорость.

Способ как объект изобретения. В этом случае математическими выражениями могут связываться как параметры режимов между собой, так и параметры режимов с параметрами объектов, над которыми производятся операции в способе. Приведем несколько примеров.

Пр и м р 1. В СССР зарегистрирован патент № 741799 (фирма ФРГ «Байер АГ») «Способ получения полиуретанмочевин». Полиуретанмочевины - незаменимое сырье для изготовления покрытий, лаков и пленок. Известен ряд изобретений в данной области, например, неакцептированные заявки ФРГ № 1694356, 2325824, 2037458.

Формула изобретения № 741799 следующая: «Способ получения полиуретанмочевин путем взаимодействия форполимера с концевыми NCO-группами, с отвердителем аминного типа в присутствии воды и растворителя, о тлич а ю и й я тем, что, с целью, повышения скорости отверждения, в качестве отвердителя используют смесь, включающую

$$
\begin{array}{ll}
\text { A } & \mathrm{H}_{2} \mathrm{~N}-\mathrm{R}-\mathrm{NH}_{2}, \\
\text { B } & \mathrm{H}_{2} \mathrm{~N}-\mathrm{R}-\mathrm{NR}_{1}, \\
\text { C } & \mathrm{R}_{1} \mathrm{~N}-\mathrm{R}-\mathrm{NR}_{1},
\end{array}
$$

где $R$-- двухвалентный алифатический, циклоалифатический или арилалифатический остаток с $2-18$ атомами С, который может содержать группировку -O- или ${ }_{X}^{\mathrm{N}}$, где $X: \mathrm{H}, \mathrm{CH}_{3-}$, 
$R_{1}$ - остаток пิосле удаления кислорода из кетона йлй а̀льдегидаิ, содержащего $2-8$ атомов С, при следующем соотношении:

$$
\begin{aligned}
& \frac{A}{B+C}=1: 10-1: 5, \\
& \frac{B}{C}=1: 1,5-1,5: 1, \\
& \frac{A+B+C}{\text { Вода }}=1: 1,4-1: 10 .
\end{aligned}
$$

Пример 2. «Способ получения полиэфиров», авторское свидетельство № 759538. Продукты реакции используют, в основном, для изготовления пластификаторов различных полимеров. Формула изобретения № 759538 следующая: «Способ получения полиэфиров путем смешения диалкиловых эфиров дикарбоновых кислот с гликолями и катализатором, нагрева полученной смеси в течение $0,5-3$ ч до $150-250^{\circ} \mathrm{C}$ при давлении $760-200$ мм рт. ст. и завершения процесса при данной температуре и уменьшении давления до $150-1$ мм рт. ст., от лича ющ и й я тем, что, с целью сокращения продолжительности процесса и снижения расходных норм, уменьшение давления проводят согласно следующей зависимости:

$$
P=P_{0}+B \lg (\tau+1)+C \lg ^{2}(\tau+1),
$$

где $P$ - давление, мм рт. ст.;

$P_{0}-$ начальное давление, мм рт. ст.;

$\tau$ - время от начала уменьшения давлення, ч;

$B, C$ - эмпирические коэффициенты, имеющие следующие значения: $B=466-2080 ; C=226-1440$.»

Вещество как объект изобретения характеризуется количественными признаками, отражающими число атомов в молекуле, количество ингредиента в смеси, число нейтронов и протонов в ядре.

\section{Выводы}

1. Для патентования наших изобретений за границей нужны авторские свидетельства с широким охватом авторских прав, что достигается использованием математических выражений.

2. Многие изобретения, в формуле которых использованы математические выражения, есть дополнительные изобретения.

3. При оформлении рассматриваемых изобретений патентоведам следует больше прибегать к помощи ЭВМ для определения охраноспособных пределов формулы изобретения.

4. Использование в формулах изобретений математических выражений открывает пути химикам-программистам, так как в этих случаях предмет охраны - это устройство или способ для его осуществления, а не сам алгоритм.

5. Математическое выражение в формулах изобретений допустимо только тогда, когда оно описывает охраноспособный признак, и недопустимо, если оно представляет собой метод расчета.

6. Более $60 \%$ изобретений, в формулах которых использованы математические выражения, сделаны в различных институтах СССР. 


\section{ЛИТЕРАТУРА}

1. Забежинский В. Н. Математические выражения в формулах изобретений. - Boпросы изобретательства, 1981, № 6, 18-20.

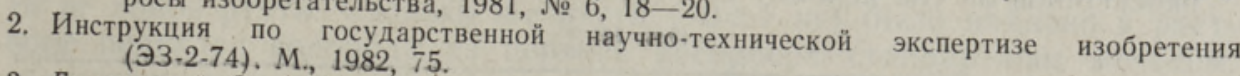

3. Горчинский C. $A$. Об использовании в формуле изобретения математических вы-

ражений. - Вопросы изобретательства, 1979 , № 3, $23-26$.
4. Бутанов A. $\Gamma$., Якунин $\Gamma$. Н. Применение математических выражений в формуле изобретения. - Вопросы изобретательства, 1975, № 11, 25-28.

Институт химии

Академии наук Эстонской ССР

Поступила в редакцию

29/II 1984

O. MOORLAT

\section{MATEMAATILISE AVALDISE KASUTAMINE KEEMIAALASTES LEIUTISVORMELEIS}

Analüüs hõlmab Nõukogude Liidus aastail 1980-1983 registreeritud leiutisi, kus leiutisvormeleis on oluliste tunnuste kirjeldamiseks kasutatud matemaatilist avaldist. Niisuguste leiutiste arv suureneb pidevalt, neist üle $60 \%$ on tehtud uurimisinstituutides. Matemaatilise avaldise kasutamine leiutisvormelis on efektiivne keemik-programmeerija seisukohalt,
et kaitsta algoritmi seadme vôi meetodi kaudu.

O. MOORLAT

\section{MATHEMATICAL EXPRESSIONS IN PATENT CLAIMS IN THE FIELD OF CHEMISTRY}

According to the analysis of inventions within the period of $1980-1983$ the number of Soviet inventions with mathematical expressions in patent claims has been constantly increasing in all fields of science and technics, including chemistry.

Several examples of patent claims with mathematical expressions are listed. Approxi. mately $60 \%$ of such inventions in the Soviet Union are executed by various institutes.

Many inventions with mathematical expressions in patent claims appeared to be

A mathematical expression in a patent claim is only possible when it describes concrete protectable features and impossible when it is merely a calculation method. 